\title{
Síndrome de Burnout no Setor de Transporte de Natal ${ }^{1}$
}

\author{
Luciana Bezerra de Souza Gianasi² \\ Livia de Oliveira Borges \\ Universidade Federal do Rio Grande do Norte
}

\begin{abstract}
RESUMO - Reconhecendo-se a importância que o ambiente de trabalho tem para a saúde mental, o objetivo desse estudo foi investigar a relação entre a síndrome de burnout e as fontes de desgaste físico e emocional no setor de transporte coletivo urbano da cidade de Natal. A pesquisa foi realizada com 412 motoristas e cobradores de duas empresas. Para coleta dos dados, aplicaram-se dois questionários e uma ficha sociodemográfica. O primeiro, construído e validado durante a pesquisa, investigou as fontes e o segundo, a síndrome. Entre os resultados, confirmou-se a prevalência da síndrome e que a principal fonte de desgaste físico e emocional que a prediz é o fator referente a conflitos de valores e ausência de equidade no ambiente de trabalho.
\end{abstract}

Palavras-chave: síndrome de burnout; condições de trabalho; transporte coletivo urbano.

\section{The Burnout Syndrome in the Transport System of Natal}

\begin{abstract}
Recognizing the importance that the work environment has on the mental health, the objective of this study was to investigate the relationship between the burnout syndrome and the sources of physical and emotional exhaustion in the urban public transport system in the city of Natal. The research was carried out with 412 professional drivers and moneychangers of two enterprises. To collect the data, two questionnaires and a social-demographic form were applied. The first questionnaire, developed and validated during the research, evaluated the sources of burnout, while the second questionnaire evaluated the factors of the referred syndrome. The results showed the prevalence of the burnout syndrome and that the main source of emotional and physical exhaustion that predicts it is a factor about conflicts of values and lack of equity at the workplace.
\end{abstract}

Keywords: burnout syndrome; work conditions; urban public transport system.

A síndrome de burnout consiste em uma reação ao estresse ocupacional crônico. Embora exista, atualmente, um número considerável de pesquisas nacionais e internacionais, ainda se tem muito a investigar sobre o assunto, principalmente no que se refere a que fatores a síndrome está associada e sobre seu processo de desenvolvimento (Gil-Monte \& Peiró, 1997; Maslach, Schaufeli \& Leiter, 2001). Mesmo assim, o que se sabe está sendo suficiente para conduzir ao seu reconhecimento legal como uma doença ocupacional, em âmbito internacional e nacional (Benevides-Pereira, 2002). Em âmbito nacional, mesmo não sendo ainda amplamente reconhecidas e divulgadas, as leis brasileiras de proteção ao trabalhador já tratam sobre a síndrome de burnout.

O Decreto $n^{\circ}$. 3048/99, de 06 de maio de 1996, que dispõe sobre a Regulamentação da Previdência Social, em seu Anexo II, que trata dos Agentes Patogênicos causadores de Doenças Profissionais, conforme previsto no Art. 20 da Lei $n^{\circ}$. 8.213/91, ao se referir aos transtornos mentais e do comportamento relacionados com o trabalho (Grupo V da CID-10), no inciso XII, aponta a "Sensação de Estar Aca-

1 Este trabalho deriva de Dissertação de Mestrado, defendida pela primeira autora deste artigo na Universidade Federal do Rio Grande do Norte, em 2003. Partes deste trabalho foram apresentadas no IV Congresso Norte-Nordeste de Psicologia (2005 - Salvador, BA) e no IX Congreso Nacional de Psicología Social (2005 - Coruña, Espanha). As autoras registram também o apoio do CNPq.

2 Endereço para correspondência: Av. Almirante Barroso, 3.977, Casa 01. Bairro Souza. Belém, PA. CEP 66613-710. Fone: (91) 8824-2694. E-mail: lucianabsg@yahoo.com.br. bado" ("Síndrome de burn-out", "Síndrome do Esgotamento Profissional") (Benevides-Pereira, 2002). A existência de tal lei no Brasil é um avanço, mas para promover sua plena aplicação faz-se necessário maior número de estudos para aperfeiçoar o diagnóstico da síndrome e maior divulgação científica.

Com relação às categorias ocupacionais que podem ser vitimadas pela síndrome, existem duas posições divergentes na literatura. A primeira defende que a síndrome ocorre somente em profissionais dos serviços de cuidados humanos. Tais profissionais estabelecem uma relação com o usuário que abrange contatos frequentes, intensos e diretos. São os casos, por exemplo, dos médicos, dos funcionários de presídios e dos policiais. A segunda posição defende que a síndrome pode ser desenvolvida em qualquer ocupação que lide com pessoas, independente do tipo de relacionamento entre o profissional e o usuário.

Pesquisas foram empreendidas com o propósito de verificar a presença da síndrome em categorias diferentes das tradicionalmente estudadas (Barbosa, 2001; Dolan, 1995; Evans \& Fischer, 1993). Entretanto, os resultados não caminharam para o estabelecimento de um consenso, e, por isso, mais pesquisas devem ser realizadas para esclarecer quais categorias ocupacionais são mais vulneráveis à síndrome (Gomes de Cádiz, San Juan, Rivero, Herce \& Achucarro, 1997).

Os trabalhadores do transporte urbano, mais especificamente, os motoristas e cobradores de ônibus, pertencem a uma das categorias ocupacionais ainda pouco exploradas nos estudos sobre a síndrome de burnout. Porém, a experiência 
profissional da primeira autora deste artigo revelou que esses trabalhadores estão expostos a condições adversas, as quais, segundo a literatura sobre a síndrome, aumentam a probabilidade de desenvolvimento da mesma, como se verá adiante. $\mathrm{O}$ excesso de trabalho, a má conservação dos ônibus, a inconveniência de horário, o baixo grau de controle sobre a tarefa, a baixa remuneração, o mau planejamento das vias urbanas, a precariedade da sinalização e da infra-estrutura das vias urbanas, a violência urbana, entre outros, são aspectos negativos do ambiente de trabalho dessa categoria. Tudo isso se torna conflitante quando são simultâneos ao apelo de tratar bem o passageiro.

Diante disso, o objetivo desta pesquisa é estudar a relação existente entre o desenvolvimento da síndrome de burnout e as fontes de desgaste físico e emocional entre motoristas e cobradores do setor de transporte via ônibus.

Em decorrência do objetivo anunciado, a presente pesquisa centrou sua atenção em dois construtos, a saber: síndrome de burnout e fontes de desgaste físico e emocional. As seções subsequentes objetivam uma conceituação dos mesmos, discutindo o segundo, conforme as características do setor de transporte urbano.

\section{Síndrome de Burnout}

Burnout é uma expressão originada no idioma inglês e que significa "queimar-se" ou "destruir pelo fogo de fora para dentro"; refere-se àquilo que deixou de funcionar por absoluta falta de energia.

Para Gil-Monte e Peiró (1997), a definição de maior aceitação é a de Maslach e Jackson (1981), segundo a qual, a síndrome é caracterizada por sentimentos de exaustão emocional, despersonalização e falta de realização pessoal no trabalho.

A Exaustão Emocional é caracterizada por um sentimento muito forte de tensão emocional que produz uma sensação de falta de energia e de recursos emocionais próprios para lidar com as rotinas da prática profissional. Essa tensão representa o aspecto de estresse individual da síndrome (Maslach, 1993; Maslach \& cols., 2001).

A Despersonalização, por sua vez, é o resultado do desenvolvimento de atitudes negativas de dureza e de distanciamento dos profissionais em relação às pessoas que se beneficiam dos seus serviços. Essa dimensão representa o aspecto interpessoal da síndrome (Maslach, 1993; Maslach \& cols., 2001).

Por último, a Diminuição da Realização Pessoal, que se refere ao aspecto de auto-avaliação do burnout, está associada ao sentimento de incompetência no trabalho (Maslach, 1993; Maslach \& cols., 2001). Trata-se, portanto, de uma síndrome na qual o trabalhador perde o sentido da sua relação com o trabalho, de forma que as coisas não lhe importam mais e qualquer esforço lhe parece inútil.

As definições que compõem o construto da síndrome de burnout podem apresentar-se, principalmente, sob duas perspectivas (Gil-Monte \& Peiró, 1997): a clínica e a psicossocial. A primeira (década de 70) caracterizou a fase inicial das pesquisas sobre o assunto, a chamada fase exploratória. A segunda caracterizou, em década posterior, a chamada fase empírica.
Na concepção clínica, o foco está voltado para aspectos individuais, como experiências de esgotamento, decepção e perda de interesse pelas atividades relacionadas ao trabalho (Freudenberger, 1974). Na concepção psicossocial, a síndrome de burnout é um processo, no qual os aspectos individuais são associados à influência do meio e ambos contribuem para o desenvolvimento da síndrome (Maslach \& Jackson, 1981; Maslach \& Leiter, 1999; Maslach \& cols., 2001).

Do ponto de vista psicossocial, alguns autores recentemente vêm focalizando mais os elementos do ambiente de trabalho (fontes de desgaste físico e emocional) como desencadeadores da síndrome. Quando as empresas não oferecem as condições necessárias para a execução das atividades ocupacionais, elas estão contribuindo para gerar estresse e desencadear processos que comprometem o bemestar psíquico do trabalhador. A síndrome de burnout pode ser apontada como um desses processos.

Comenta-se aqui que essa tendência a focalizar o papel do ambiente tem importância ética, pois que implicitamente assume que as diferenças entre os indivíduos no ambiente de trabalho devem ser acolhidas, devendo a organização oferecer os meios para compensá-las quando necessário. E, ao mesmo tempo, rejeita implicitamente que os indivíduos sejam vítimas de discriminação social por suas características psíquicas.

\section{Fontes de Desgaste Físico e Emocional}

Os aspectos do ambiente de trabalho que também contribuem para o desencadeamento da síndrome de burnout são denominados por Maslach e Leiter (1999) de fontes de desgaste físico e emocional. Estes autores destacam o excesso de trabalho, a falta de controle, a recompensa insuficiente, a falta de equidade, o colapso na união e os conflitos de valores como sendo as seis fontes, do ambiente de trabalho, que contribuem para a síndrome de burnout.

A primeira fonte, excesso de trabalho, refere-se a jornadas intensas que exigem mais tempo, mais rapidez, mais atenção ou mais ativação ou, ainda, consistem em tarefas complexas, implicando, mais provavelmente, a exaustão por sobrecarga. $\mathrm{O}$ ambiente de trabalho dos profissionais que transportam pessoas em ônibus coletivo apresenta aspectos negativos e conflitantes como os congestionamentos, a precariedade dos veículos (ônibus) e a violência urbana. Tais aspectos tornam o trabalho mais complexo (o motorista lida com vários fatores ao mesmo tempo), mais intenso (exige mais tempo de trabalho), gerando exaustão por sobrecarga. A complexidade, a intensidade e a exaustão, por sua vez, são aspectos que caracterizam o excesso de trabalho como fonte de desgaste.

A falta de controle sobre a tarefa, segunda fonte de desgaste, refere-se à carência de possibilidades para exercer e desenvolver a autonomia no trabalho, seja por falha e deficiência nos processos organizacionais, seja pela própria natureza da tarefa, que não requer criatividade e autonomia.

A ausência de controle pode ser observada quando as pessoas não possuem liberdade para estabelecer prioridades no trabalho e decidir sobre o uso de recursos, bem como quando se sentem impedidas de resolver os problemas do dia-a-dia 
de trabalho. A falta de controle também acontece quando as regras estabelecidas não são possíveis de serem cumpridas, seja pela falta de recursos, seja pela insuficiente capacitação para a tarefa. O congestionamento no trânsito e a precariedade dos veículos podem contribuir para a impotência do motorista frente às exigências de trabalho (cumprimento de horário, por exemplo), demonstrando o seu baixo controle sobre sua tarefa.

Outro fator que, aliado ao cumprimento de horário, também se apresenta como fonte de conflito é o controle do número de passageiros transportados. Além da exigência do cumprimento do horário e outros agravantes do trânsito, o motorista e o cobrador precisam estar atentos às solicitações dos passageiros para embarque, pois a diminuição do número médio de passageiros transportados, por viagem, pode ser motivo para que a dupla (cobrador e motorista) passe a ser observada.

A remuneração insuficiente, terceira fonte de desgaste, é subdivida em recompensas extrínsecas e intrínsecas. A primeira refere-se às recompensas financeiras, e a segunda, às recompensas afetivas (reconhecimento, respeito, admiração) e ao sentimento de prazer na realização das tarefas. As dificuldades enfrentadas, atualmente, no setor constituem-se fonte de desgaste, à medida que podem estar refletindo no enfraquecimento das recompensas oferecidas aos empregados como reconhecimento, remuneração e outros benefícios. Além disso, um ambiente de trabalho precário implica processos organizacionais deficientes, os quais podem contribuir negativamente no sentimento de satisfação de quem trabalha.

O colapso da união, quarta fonte de desgaste, é definido como a diminuição progressiva do apoio e do respeito mútuo entre as pessoas no trabalho; diminuição essa que contribui para o aparecimento de conflitos entre elas e para o sentimento crescente de isolamento, caracterizando-se dessa forma a fragmentação das relações interpessoais. A manutenção do número de passageiros transportados pode ser um fator gerador de competição entre as duplas (que trabalham em horários próximos), no momento em que essas passam a concorrer por passageiros. Tal competição pode contribuir para fragmentar as relações interpessoais, caracterizando a quarta fonte referida.

A ausência de equidade, quinta fonte de desgaste, é entendida como sinônimo de injustiça no trabalho, devido à distribuição injusta de recursos, benefícios, promoção, tratamento, gerando um sentimento de desconfiança mútua entre empresa e empregado.

A sexta fonte de desgaste refere-se aos valores conflitantes entre empresa e empregados, decorrentes, muitas vezes, da descompensação entre o que é oferecido ao empregado e o que é exigido dele. É comum a empresa exigir dedicação e ótimos índices de produção e em contrapartida não oferecer os benefícios na mesma proporção, gerando um sentimento de descredibilidade do funcionário em relação aos valores da empresa.

Em virtude do ambiente descrito, motoristas e cobradores de ônibus têm oferecido atendimento inadequado ao usuário; fato que se expressa por condutas tais como: dirigir em alta velocidade; frear bruscamente negligenciando a vida dos passageiros; não atender aos pedidos de embarque e desembarque; recusar a prestar informações; oferecer um tratamento agressivo e pouco atencioso ao passageiro e cometer outras infrações de trânsito. Tais condutas podem ser compreendidas como manifestação da síndrome.

O cenário de concorrência tem obrigado as empresas de transporte a adotarem uma nova mentalidade em relação aos serviços oferecidos. Atualmente, o termo adotado para denominar cada indivíduo transportado deixa de ser passageiro e passa a ser cliente, a quem os motoristas e os cobradores devem tratar com atenção e respeito.

Diante disso, é possível observar a contradição que envolve o trabalhador de transporte, que, mesmo não tendo condições adequadas para desenvolver o seu trabalho, é constantemente convocado a oferecer bons serviços à população. Como oferecer ao próximo um tratamento de atenção, se não há um tratamento condigno no exercício da profissão? A situação que se apresenta pode estar gerando desconfiança por parte do empregado com relação aos valores organizacionais. A contradição referida é fruto do conflito de valores entre o que a organização espera do empregado e o que ela oferece a ele, constituindo-se em fonte de desgaste emocional.

Indagou-se, então, o que as informações sobre o setor de transporte podiam indicar sobre a realidade apresentada. Estudo realizado pela Associação Nacional das Empresas de Transportes Urbanos (NTU), publicado no anuário de 1999, chama a atenção para o fato de que o transporte coletivo urbano vem, desde 1995, vivenciando um processo contínuo de degradação. Esse processo é caracterizado principalmente pela perda da demanda de passageiros e diminuição da oferta de serviços.

De acordo com o mesmo estudo, tal realidade encontra-se diretamente relacionada à falta de infra-estrutura viária adequada, à concorrência predatória do transporte ilegal, à alta carga de tributos e encargos (que não considera a essencialidade do serviço) e ao descontrole das gratuidades e benefícios tarifários. Esses aspectos contribuem diretamente para onerar os custos dos serviços de transporte, ocasionando a redução da demanda de usuários e a diminuição da oferta de serviços. A redução na demanda também está associada à queda do poder aquisitivo dos usuários do transporte coletivo.

Considerando o acima exposto, a presente pesquisa tomou como ponto de partida a seguinte questão geral: Qual a relação entre a síndrome de burnout e as fontes de desgaste físico e emocional? A busca de respostas para esse problema de pesquisa, por sua vez, norteou-se pelas seguintes questões específicas: Quais as fontes de desgaste físico e emocional que permeiam às condições de trabalho de motoristas e cobradores de ônibus em Natal? Qual a prevalência de burnout nesses profissionais? As fontes de desgaste físico e emocional têm relação com a síndrome de burnout?

\section{Método}

Na presente pesquisa, as variáveis são os componentes dos construtos - síndrome de burnout e fontes de desgaste físico e emocional - conceitualmente descritos na introdução do presente artigo. O método de pesquisa utilizado é classificado como descritivo, do tipo que explora relações entre variáveis, mas que não usa técnicas de manipulação de 
variáveis. Assim, consiste em uma tentativa de descrever a realidade por meio de pesquisa de campo com questionários estruturados, e de avaliar a capacidade preditiva de uma variável em relação à outra (Tripodi, 1975).

\section{Participantes}

Participaram da pesquisa 412 pessoas do sexo masculino, das quais $61,3 \%$ eram motoristas e $38,7 \%$ eram cobradores, com média de seis anos no exercício de tais funções na empresa. O critério de inclusão dos motoristas e cobradores seguia a disponibilidade dos mesmos nos momentos das visitas para coletar os dados, portanto, formou-se uma amostra acidental. O termo "acidental" é utilizado, distinguindo do termo aleatório. Quando se menciona amostra aleatória, refere-se a uma amostra em que a inclusão e a exclusão dos indivíduos da população na amostra supõem as mesmas chances. Quando se diz que uma amostra é acidental, considera-se que a inclusão dos indivíduos tem uma elevada casualidade, porém é afetada por algum critério como acessibilidade do indivíduo ou desejo de colaborar com a pesquisa (Kish, 1996; Sarriá, Guardiã \& Freixa, 1999; Scarparo, 2000).

\section{Instrumentos}

A prevalência da síndrome de burnout foi avaliada a partir da aplicação da "Escala de Caracterização do Burnout" (ECB), de autoria de Tamayo e Trócoli (2000). Construída no Brasil, a ECB (segunda versão) é composta por 46 itens que mensuram três fatores: a Exaustão Emocional (alfa=0,93), a Desumanização $(\mathrm{alfa}=0,84)$ e a Decepção $(\mathrm{alfa}=0,90)$. A validade de construto do questionário foi avaliada pela aplicação de análise fatorial. Os fatores explicaram 46\% da variância e os seus itens apresentaram carga superior a 0,40 . As características psicométricas de tal instrumento foram melhores do que aquelas apontadas para outros instrumentos na literatura (Tamayo \& Tróccoli, 2005).

$\mathrm{O}$ instrumento para avaliação das fontes de desgaste foi elaborado e validado durante a pesquisa e denominado Questionário de Avaliação das Fontes de Desgaste Físico e Emocional (QFD). O questionário foi planejado com 46 itens (escala tipo Likert).

A análise fatorial do questionário apontou a existência de dois fatores empíricos, e não de seis como se previa, a saber: (F1) Conflito de Valores e Ausência de Equidade e (F2) União e Recompensa. O primeiro fator se refere a vivências de uma relação de desconfiança mútua com a empresa, além da percepção de uma descompensação entre o que lhes é oferecido e o que lhes é exigido (injustiça na empresa). O segundo fator aborda as relações interpessoais e as formas de recompensa econômicas e simbólicas. A extração dos dois fatores explica, no total, 26,70\% da variância, sendo $20,7 \%$ pelo primeiro fator e $5,9 \%$ pelo segundo. A consistência dos fatores foi estimada pelos coeficientes alfas de Cronbach, que foram respectivamente de 0,86 e 0,72 , indicando boa confiabilidade para os dois fatores (Gianasi, 2004).
Os resultados da análise fatorial sugerem que não há uma definição/diferenciação clara entre os seis fatores. É provável que a precariedade do ambiente de trabalho dificulte uma diferenciação precisa e clara dos processos de trabalho, o que leva a distinções grosseiras sobre o que se vivencia nesse ambiente.

Aplicou-se também uma ficha sociodemográfica (idade, escolaridade etc.) e ocupacional (tempo de serviço, função atual etc.) para construir a descrição da amostra, bem como poder explorar se esses aspectos intermedeiam a relação entre a prevalência da síndrome de burnout e as fontes de desgaste físico e emocional.

\section{Procedimento}

Tendo em vista a consecução do objetivo da pesquisa, planejou-se seu desenvolvimento em duas empresas de transporte urbano de Natal. A aplicação dos questionários foi realizada nos terminais de ônibus, em horário de expediente, nos intervalos entre as viagens (variava entre $30 \mathrm{e}$ 40 minutos). Ao final do preenchimento, o questionário era depositado, pelo próprio respondente, em uma urna, visando garantir o anonimato dos participantes.

\section{Análise de dados}

As respostas aos questionários foram registradas em banco de dados do SPSS (Statistical Package of Social Science). Iniciaram-se as análises por uma etapa de exploração dos dados, objetivando conferir a exatidão da digitação e o atendimento das exigências que precedem as análises multivariadas (Tabachnick \& Fidell, 2001. Em seguida, realizaram-se as análises estatísticas para responder as questões de pesquisa. Tais análises serão identificadas e descritas paulatinamente à apresentação dos resultados, priorizando a síntese expositiva.

\section{Resultados}

Para investigação da avaliação dos participantes a respeito dos fatores empíricos, Conflito de Valores e Ausência de Equidade (F1) e União e Recompensa (F2), estimaram-se os escores ( 0 a 5 ) nos dois fatores por meio da média ponderada (pelas cargas dos itens no fator) dos pontos atribuídos aos itens pelos participantes. Em seguida, estimaram-se a média e o desvio-padrão dos escores em cada fator para a amostra, bem como se apurou a frequência por intervalos da distribuição de escores nos fatores (Tabela 1).

Os resultados revelaram que os empregados fazem uma avaliação mais desfavorável do seu ambiente de trabalho, no que se refere aos aspectos que constituem o primeiro fator. Entretanto, são mais condescendentes no tocante às relações interpessoais entre colegas e chefes e às formas de recompensa oferecidas pela organização.

É provável que na origem dos conflitos de valores entre a empresa e os funcionários (Fator 1) esteja, entre outros 
Tabela 1. Média, desvio-padrão e frequências, por intervalos, relativos aos fatores.

\begin{tabular}{ccc}
\hline & \multicolumn{2}{c}{ Fatores } \\
Frequência de & $\mathrm{F} 1$ & $\mathrm{~F} 2$ \\
participantes & Conflito de valores & União e recom- \\
por intervalo & e ausência de & pensa \\
\hline $\mathrm{x} \leq 1$ & equidade & - \\
$1<\mathrm{x} \leq 2$ & - & $1,6 \%$ \\
$2<\mathrm{x} \leq 2,8$ & $14,0 \%$ & $16,0 \%$ \\
$2,8<\mathrm{x} \leq 3,6$ & $\mathbf{3 5 , 9 \%}$ & $\mathbf{3 7 , 2} \%$ \\
$3,6<\mathrm{x} \leq 4,4$ & $\mathbf{2 9 , 7 \%}$ & $\mathbf{3 5 , 1 \%}$ \\
$\mathrm{x}>4,4$ & $17,8 \%$ & $10,1 \%$ \\
\hline Média & $2,6 \%$ & 3,5 \\
Desvio Padrão & 2,9 & 0,71 \\
\hline
\end{tabular}

aspectos, a já mencionada contradição, na qual o trabalhador de transporte, mesmo não tendo um ambiente adequado de trabalho, é constantemente convocado a oferecer bons serviços à população.

A soma de todos os aspectos que compõem o ambiente de trabalho de motoristas e cobradores - como os congestionamentos diários, a pressão pelo cumprimento de horário, a precariedade dos veículos e das estradas, o risco de acidentes, a violência urbana, os eventos imprevistos no trânsito, a responsabilidade pelo pagamento de algumas peças, dentre outros - contrasta com as atitudes exigidas pela empresa aos motoristas e cobradores no que se refere à excelência no atendimento ao usuário.

É possível que as relações interpessoais entre os colegas e as recompensas oferecidas pela organização funcionem como um contraponto à vivência do conflito de valores. Embora a competição entre colegas pelo número de passageiros tenha sido uma questão levantada pelos funcionários, como citado anteriormente, provavelmente esta tenha tomado uma dimensão menor diante dos outros problemas que se apresentam ou esteja se representando como conflitos de valores e não diretamente nas interações.

A distribuição dos escores dos participantes mostra que o primeiro fator foi avaliado de forma semelhante pelos empregados em ambas as empresas (Qui-quadrado=0.80; $p<0.93$ ). Nas duas empresas, os participantes apontam para a existência de uma relação negativa-moderada, entre eles mesmos e a organização, de desconfiança mútua, considerando os escores atribuídos à existência de conflito entre os valores defendidos e exigidos pela organização, bem como às atitudes de injustiça nas empresas.

Com relação ao segundo fator, as análises indicaram que os empregados da segunda empresa possuem uma avaliação mais positiva de aspectos relativos às relações interpessoais e recompensas do que os empregados da primeira empresa $\left(\chi^{2}=11,2 ; p=0,02\right)$.
Para avaliação da ocorrência da síndrome de burnout, o primeiro passo foi estimar os escores nos fatores por meio da média aritmética dos pontos atribuídos pelos participantes da amostra aos itens de cada fator, seguindo-se o procedimento adotado por Tamayo (1997).

Observou-se, então, que as médias nos fatores da síndrome de burnout (Exaustão Emocional: $\mathrm{M}=1,97$ e $\mathrm{DP}=0,83$; Desumanização: $M=1,93$ e $\mathrm{DP}=0,82$; Decepção: $\mathrm{M}=2,00$ e $\mathrm{DP}=0,80$ ) revelam que a tendência geral dos indivíduos da amostra é apresentar sentimentos de exaustão emocional, despersonalização e diminuição da realização pessoal, abaixo do ponto médio da escala (de 1 a 5) que é o escore 3,0.

Dentre os três fatores, os participantes apresentaram a média mais alta no fator Decepção; fato que revela que possivelmente esses profissionais estão vivenciando um sentimento de desânimo, de frustração e de inadequação no trabalho. Provavelmente, o sentimento de decepção, que está relacionado ao sentimento de incompetência, esteja ligado à questão da falta de controle que os profissionais possuem em relação à sua tarefa.

Os escores de Exaustão Emocional apresentaram o maior desvio-padrão, indicando que há uma maior dispersão nesse fator. No fator Desumanização, os participantes apresentaram a média mais baixa e isso pode estar ligado ao fato de esses trabalhadores terem dificuldades em declarar sentimentos dessa natureza, já que contradiz exigências da empresa de oferecer ao cliente um bom tratamento. De acordo com Tamayo (2002), é possível que a interferência da desejabilidade social sobre as respostas apresentadas pelos sujeitos aos itens do fator Despersonalização iniba o relato da frequência com que alguns profissionais experimentam sentimentos e atitudes dessa natureza no seu relacionamento com os usuários.

Em decorrência dessas considerações, pode-se afirmar que a média dos escores brutos diz pouco do desenvolvimento da síndrome de burnout, pois grupos diferentes podem ter padrões diferentes do que seja tolerável nos três fatores da síndrome. Por isso, resolveu-se explorar as distribuições de frequência pela técnica usada desde Maslach (Tamayo, 1997): usar os percentis para nortear a classificação dos escores. Identificaram-se os dois percentis (os pontos que dividem a distribuição dos escores dos participantes, em cada fator, em três partes iguais quanto ao número de participantes). Realizou-se, então, a classificação dos intervalos de escores, designando-os de: baixo, médio e alto.

A vivência da síndrome, como já comentado na introdução, caracteriza-se pelo desenvolvimento dos três fatores. Se três níveis estão sendo considerados na distribuição dos escores nos fatores, então hipoteticamente há 27 possíveis combinações de fatores. Para identificar tais combinações, realizou análise de cluster.

As combinações nas quais o processo de desenvolvimento do burnout encontra-se mais avançado e mais evidente são aquelas em que coexistem níveis altos e médios nos três fatores (Tabela 2). Há 41,4\% da amostra (156 pessoas) que apresentam tal tipo de combinação, sendo que $13 \%$ desses participantes (49 pessoas) estão em um nível máximo, combinando escores altos nos três fatores. 
Tabela 2. Análise de Cluster que combina níveis alto e médio.

\begin{tabular}{lccccccccc}
\hline \multirow{2}{*}{ Fatores } & \multicolumn{7}{c}{ Configurações } \\
\cline { 2 - 8 } & 1 & 2 & 3 & 4 & 5 & 6 & 7 & 8 \\
\hline Exaustão Emocional & Médio & Alto & Médio & Médio & Alto & Alto & Médio & Alto \\
Desumanização & Médio & Médio & Alto & Médio & Alto & Médio & Alto & Alto \\
Decepção & Médio & Médio & Médio & Alto & Médio & Alto & Alto & Alto \\
\hline Participantes (156/377) & 14 & 13 & 18 & 12 & 14 & 26 & 10 & 49 \\
\hline
\end{tabular}

A Tabela 2 apresenta oito configurações, as quais apontam para variados níveis da síndrome, que vão desde um nível tipicamente médio (combinando escores médios nos três fatores) até um nível muito elevado (combinando escores altos nos três fatores). Além disso, as combinações de 1 a 4 representam um nível acentuado de desenvolvimento da síndrome e são constituídas por $15,1 \%$ da amostra (57 pessoas). As combinações 5, 6 e 7 representam uma aproximação do nível estremado da síndrome, o que corresponde a 28,9\% da amostra (109 pessoas).

Os resultados da análise de clusters apontaram a presença de uma tendência endêmica da síndrome de burnout entre os motoristas e cobradores do setor de transporte. Esses resultados são equivalentes aos das pesquisas realizadas em Natal, com profissionais de saúde (Borges, Argolo, Pereira, Machado \& Silva, 2002; Tamayo, Argolo \& Borges, 2005) e da educação (Dantas, 2003). A prevalência da síndrome deve ser compreendida como um indicativo de que medidas devem ser adotadas no sentido de diminuí-la e evitar que profissionais que apresentaram, no momento da coleta dos dados, um nível baixo da síndrome, avancem no desenvolvimento desta. As organizações não devem perder de vista que a vivência da síndrome pelos motoristas e cobradores pode comprometer a qualidade dos serviços prestados pelas empresas.

Para avaliar a capacidade preditiva dos escores dos fatores das fontes de desgaste em relação aos escores nos fatores da síndrome de burnout e se tal previsão está mediada por variáveis sociodemográficas e ocupacionais, desenvolveramse três análises de regressão linear hierárquica, uma para cada fator da síndrome de burnout. Todas as análises ocorreram por meio de três blocos de variáveis independentes: o primeiro abrangeu os dois fatores referentes às fontes de desgaste; o segundo bloco envolveu as variáveis funcionais como empresa em que trabalha, função atual, tempo de serviço, renda familiar e nível de instrução; o terceiro e último bloco envolveu as variáveis que podem ser tomadas como indicadores de apoio social, que são ser católico ou não, ser casado ou não e ter filhos ou não.

A Tabela 3 apresenta as regressões que possuem como variável dependente a Exaustão Emocional (FB1). É possível perceber, na primeira regressão, que os escores do fator Conflito de Valores e Ausência de Equidade nas Organizações (FC1) explicam sozinhos $29 \%$ da variância dos escores de Exaustão Emocional.

A regressão subsequente explica $30 \%$ da proporção da variância, ou seja, 1\% a mais que a primeira, quando se inclui o preditor empresa (FS1). Esse preditor não se mostra interagindo com o primeiro, já que não houve alteração relevante do coeficiente 'beta' da primeira regressão para a segunda.

$\mathrm{O}$ preditor mais forte (FC1) apresenta uma relação diretamente proporcional com Exaustão Emocional (beta positivo), o que significa que quanto mais os participantes da amostra percebem Conflito de Valores e Ausência de Equidade nas Organizações, maior a probabilidade de que se intensifique a vivência de Exaustão Emocional, componente da síndrome de burnout. Considerando-se que os escores desse preditor (FC1) se encontram em níveis altos da escala, compreende-se que FC1 está contribuindo para a prevalência da síndrome entre motoristas e cobradores. Como a síndrome de burnout é um fenômeno processual, a manutenção do fator FC1 poderá, progressivamente, acentuar tal prevalência da síndrome.

Analisando-se a regressão (Tabela 4), cuja variável dependente é a Desumanização (FB1), percebe-se que o fator Conflitos de Valores e Ausência de Equidade (FC1) explica, sozinho, $21 \%$ da variância. Esse dado aponta para o fato de que nem as variáveis funcionais nem as de apoio social, in-

Tabela 3. Análises de regressão hierárquica (variável dependente = Exaustão Emocional, FB1).

\begin{tabular}{|c|c|c|c|c|}
\hline Regressões/Variáveis Independentes & $\mathrm{R}^{2}$ & Beta & $\mathrm{T}$ & Significância \\
\hline \multicolumn{5}{|c|}{ Primeira regressão } \\
\hline (Constante) & & & 6,27 & $<0,01$ \\
\hline FC1 - Conflitos de Valores e Ausência de Equidade & 0,29 & 0,53 & 9,38 & $<0,01$ \\
\hline \multicolumn{5}{|c|}{ Segunda regressão } \\
\hline (Constante) & & & $-6,44$ & $<0,01$ \\
\hline FC1 - Conflitos de Valores e Ausência de Equidade & 0,30 & 0,54 & 9,58 & $<0,01$ \\
\hline FS1 - Empresa & & $-0,13$ & $-2,34$ & $<0,01$ \\
\hline
\end{tabular}


Tabela 4. Análises de regressão hierárquica (variável dependente = Desumanização, FB2)

\begin{tabular}{|c|c|c|c|c|}
\hline Regressões/ Variáveis Independentes & $\mathrm{R}^{2}$ & Beta & $\mathrm{T}$ & Significância \\
\hline \multicolumn{5}{|c|}{ Primeira Regressão } \\
\hline (Constante) & & & 10,95 & $<0,01$ \\
\hline FC1 - Conflitos de Valores e Ausência de Equidade & 0,21 & 0,45 & 7,54 & $<0,01$ \\
\hline
\end{tabular}

cluídas no estudo, foram capazes de oferecer previsibilidade aos escores de Desumanização.

Destacando-se, então, a Tabela 5, na qual a regressão possui como variável dependente a Decepção, pode-se observar que o fator União e Recompensa (FC2) explica, sozinho, $20 \%$ dos escores da variância em Decepção. Considerando-se que FC2 é inversamente proporcional à Decepção, pode-se esperar que o aumento do primeiro preditor (FC2) seja acompanhado por baixos níveis do segundo (FB3).

A regressão subsequente explica $25 \%$ da variância, ou seja, $5 \%$ a mais que a primeira, e isso ocorre com a inclusão do preditor FC1 que também é capaz de predizer a variável dependente, só que numa relação diretamente proporcional. Conclui-se que, quanto maiores os conflitos de valores e a injustiça, maiores os níveis de Decepção.

Nessa mesma equação de regressão, observa-se que os escores no fator União e Recompensa (FC2) continuam sendo os principais preditores, pois que a esse fator corresponde o maior coeficiente beta $(-0,32)$. Entretanto, esse coeficiente decresceu em relação à primeira equação. Isto significa que os escores do fator $\mathrm{FC} 1$ intermedeiam a relação existente entre os escores no fator FC2 e os de Decepção (FB3). É importante lembrar que os fatores FC1 e FC2 são correlacionados entre si, o que justificou a aplicação de análise fatorial oblíqua (Gianasi, 2004).

A terceira equação explica, por sua vez, $26 \%$ da variância dos escores no fator Decepção (FB3), ou seja, apenas $1 \%$ a mais que a equação anterior. Isso quer dizer que embora a variável dependente "ser católico" (FS2) seja um preditor de FB3, seu poder de predição não é tão forte para causar aumentos mais significativos na explicação da variância. A variável FS2 oferece previsibilidade aos escores da variável dependente (FB3) numa relação inversamente proporcional: o fato dos participantes estarem ligados a uma religião (predominantemente católica) diminui os níveis do fator Decepção.

\section{Discussão}

Em relação à primeira questão específica - Quais as fontes de desgaste físico e emocional que permeiam as condições de trabalho de motoristas e cobradores? -, foi possível identificar duas fontes de desgaste, a saber: (1) Conflitos de Valores e Ausência de Equidade nas relações com a organização, e (2) União e Recompensa. Os participantes apontaram vivenciar uma relação de desconfiança mútua com a empresa, além de perceberem uma descompensação entre o que lhes é oferecido e o que lhes é exigido. Por outro lado, avaliaram como sendo positivas as relações interpessoais e as formas de recompensa, mais especificamente as simbólicas. Assim, embora o fator União e Recompensa possa ser uma fonte de desgaste, para a maioria dos participantes não o é.

Esses dados possuem uma relação contrária com a suposição de que os participantes fariam uma avaliação

Tabela 5. Análises de regressão hierárquica (variável dependente = Decepção, FB3)

\begin{tabular}{|c|c|c|c|c|}
\hline Regressões/Variáveis Independentes & $\mathrm{R}^{2}$ & Beta & $\mathrm{T}$ & Significância \\
\hline \multicolumn{5}{|c|}{ Primeira Regressão } \\
\hline (Constante) & & & 24,46 & $<0,01$ \\
\hline FC2 - União e Recompensa & 0,20 & $-0,45$ & $-9,25$ & $<0,01$ \\
\hline \multicolumn{5}{|c|}{ Segunda Regressão } \\
\hline (Constante) & & & $-10,38$ & $<0,01$ \\
\hline FC2 - União e Recompensa & 0,25 & $-0,32$ & $-5,54$ & $<0,01$ \\
\hline FC1 - Conflitos de Valores e Ausência de Equidade & & 0,25 & 4,42 & $<0,01$ \\
\hline \multicolumn{5}{|c|}{ Terceira Regressão } \\
\hline (Constante) & & & $-10,72$ & $<0,01$ \\
\hline FC2 - União e Recompensa & 0,26 & $-0,31$ & $-5,50$ & $<0,01$ \\
\hline FC1 - Conflitos de Valores e Ausência de Equidade & & 0,25 & 4,46 & $<0,01$ \\
\hline FS2 - Ser Católico & & $-0,12$ & $-2,51$ & $<0,01$ \\
\hline
\end{tabular}


negativa das recompensas e manteriam relações interpessoais fragmentadas. Entretanto, é provável que as relações interpessoais e as formas de recompensa, mais especificamente as simbólicas, sejam a maneira encontrada tanto pelo empregado, quanto pela empresa para compensar os conflitos de valores e a falta de justiça. Além disso, cabe ressaltar que uma avaliação positiva das recompensas materiais pode ser fruto de uma atitude de alienação por parte do empregado em relação à sua situação na empresa. $O$ contexto geral de desemprego também pode estar contribuindo para que esses trabalhadores avaliem positivamente as recompensas recebidas posto que, provavelmente no ato de avaliá-las, consideram implicitamente (mesmo sem haver solicitação neste sentido) as raras oportunidades no mercado de trabalho e a qualidade destas.

Entre as fontes da síndrome pesquisadas, os participantes de ambas as empresas percebem mais os Conflitos de Valores e Ausência de Equidade do que União e Recompensação. Esse fato significa ser antes um problema ocupacional do que organizacional, no sentido de que ultrapassa o ambiente da empresa e, provavelmente, tende a se generalizar a todos os motoristas e cobradores.

Tais problemas, provavelmente, estão relacionados aos fatores externos vivenciados por esses profissionais no diaa-dia do trabalho, anteriormente apontados. Esse cenário de 'precarização' encontra-se intrinsecamente relacionado à crise vivenciada pelo setor de transportes coletivos e, por consequência, o planejamento de estratégias de intervenção requer considerar a necessidade de mudanças que vão além do nível organizacional e atingem um nível mais amplo: a definição e ou incremento de políticas públicas voltadas para área de transporte e para o controle das condições de trabalho.

Com relação à segunda questão específica - Qual a prevalência de burnout nos motoristas e cobradores de transporte coletivo (ônibus) em Natal? - , as respostas dos participantes e as análises realizadas também propiciaram verificar a prevalência da síndrome de burnout na amostra investigada, sendo Decepção o sintoma mais forte.

A ocorrência da síndrome em níveis moderado e acentuado acontece em uma proporção equivalente aos indicados em pesquisas anteriores com profissionais de saúde e de educação (Borges \& cols., 2002; Dantas, 2003; Tamayo \& cols., 2005), caracterizando uma tendência endêmica.

Os resultados também permitiram responder a terceira questão de pesquisa - As fontes de desgaste que caracterizam as condições de trabalho desses profissionais relacionam-se com o desenvolvimento da síndrome de burnout? -, indicando que as duas fontes de desgaste físico e emocional são preditores dos fatores da síndrome de burnout.

Tomando-se os três fatores da síndrome de burnout, pode-se perceber que a primeira fonte de desgaste físico e emocional é forte preditora de Exaustão Emocional e, considerando-se que a síndrome é um fenômeno processual, é possível que no longo prazo a manutenção desses conflitos e da falta de justiça possa ampliar sua prevalência. Além disso, identificou-se que essa fonte de desgaste também prediz os outros dois fatores da síndrome, reforçando ainda mais a hipótese de que o aumento dos conflitos de valores e de injustiça no trabalho possa estar contribuindo para a prevalência da síndrome. Em referência ainda ao fator de Exaustão Emocional, assinala-se que os resultados corroboram também a observação de que a prevalência da síndrome varia com a empresa em que o empregado trabalha e, dessa forma, deve haver aspectos específicos, ou não genéricos ao setor de transporte, que estão contribuindo para a endemia. Nesse sentido, há ações a serem realizadas no âmbito organizacional para prevenir o desenvolvimento da síndrome.

No que se refere à segunda fonte, União e Recompensa, ela também foi identificada como preditora para o fator Decepção da síndrome de burnout, agindo em relação a ele numa relação inversa. Dessa forma, a manutenção dessa fonte pode contribuir para a diminuição do fator Decepção.

Em síntese, as fontes de desgaste físico e emocional explicam proporções relevantes da prevalência da síndrome. Embora as fontes de desgaste, nos tipos identificados por Maslach e Leiter (1999), não se configurem enquanto categorias que estruturam as cognições desses trabalhadores, os fatores empiricamente encontrados (FC1 e FC2) apresentaram-se capazes de predizer os fatores da síndrome de burnout.

Considerando que a síndrome de burnout já é reconhecida no Brasil, pelo Ministério do Trabalho, como doença ocupacional, como referido anteriormente, a mesma deve passar a ser uma preocupação das organizações, inclusive, para evitar sofrerem penalidades trabalhistas.

Os resultados deste trabalho apontaram a importância de variáveis do ambiente de trabalho para a predição dos fatores de burnout. Recomenda-se que as estratégias de combate à síndrome sejam desenvolvidas em âmbito organizacional e de políticas públicas.

\section{Referências}

Associação Nacional das Empresas de Transportes Urbanos - NTU (1999). Anuário 1999. Retirado em 02/04/2003, de http:// www.ntu.org.br/frame_publicacoes9.htm.

Barbosa, R. M. (2001). A relação entre a síndrome de burnoute o comprometimento organizacional em gestores de empresa estatal. Dissertação de Mestrado, Universidade de Brasília, Brasília.

Benevides-Pereira, A. M. T. (2002). Burnout: quando o trabalho ameaça o bem-estar do trabalhador. São Paulo: Casa do psicólogo.

Borges, L. O., Argolo, J. C. T., Pereira, A. L. S., Machado, E. A. P., \& Silva, W. S. (2002). A Síndrome de burnout e os valores organizacionais: um estudo comparativo em hospitais universitários do RN. Psicologia: Reflexão e Crítica, 15, 189-200.

Dantas, E. A (2003). A relação entre a saúde organizacional e a síndrome de burnout. Dissertação de Mestrado, Universidade Federal do Rio Grande do Norte, Natal.

Dolan, S. L. (1995). Individual, organizational and social determinants of managerial burnout: Theorical and empirical update. Em R. Crandall \& P. L. Perrewé (Orgs.), Occupational stress handbook (pp. 223-237). Washington: Taylor \& Francis.

Evans, G. W., \& Fischer, D. G. (1993). The nature of burnout: A study of the three-factor model of burnout of human service and non-human service samples. Journal of Occupational and Organizational Psychology, 66, 29-38. 
Freudenberger, H. (1974). Staff burn-out. Journal of Social Issues, 30, 159-165.

Gianasi, L. B. S. (2004). As fontes de desgaste fisico e emocional e a síndrome de burnout no setor de transporte coletivo urbano de Natal. Dissertação de Mestrado, Universidade Federal do Rio Grande do Norte, Natal.

Gil-Monte, P., \& Peiró, J. M. (1997). Desgaste psíquico en el trabajo: El síndrome de quermarse. Madrid: Síntesis Psicologia.

Gomes de Cádiz, B. T., San Juan, C., Rivero, A. M., Herce, C., \& Achucarro, C. (1997). Burnout profesional? Un problema nuevo? Reflexiones sobre el concepto y su evaluación. Revista de Psicología del Trabajo y de las Organizaciones, 13, 23-50.

Kish, L. (1996). Diseño estadístico para la investigación. Madri: Siglo Veintiuno de España Editores.

Maslach, C. (1993). Burnout: A multidimensional perspective. Em W. B. Schaufeli, C. Maslach \& T. Marek (Orgs.), Professional burnout: Recent developments in teory and research (pp. 19-32). Washington: Taylor \& Francis.

Maslach, C., \& Jackson, S. E. (1981). Maslach Burnout Inventory. Palo Alto: Consulting Psychologist Press.

Maslach, C., \& Leiter M. (1999). Trabalho: fonte de prazer ou desgaste? Campinas: Papirus.

Maslach, C., Schaufeli, W., \& Leiter, M. (2001). Job burnout. Annual Review of Psychology, 52, 397-422.

Sarriá, A., Guardiã, J., \& Freixa, M. (1999). Introducción a la estadística en Psicología. Barcelona: Ediciones de la Universitat de Barcelona.

Scarparo, H. (2000). Psicologia e pesquisa. Porto Alegre: Sulina.

Tabachnick, B. G., \& Fidell, L. S. (2001). Using multivariate statistics. New York: Harper Collins Publishers.
Tamayo, M. R. (1997). Relação entre a sindrome de burnout e os valores organizacionais no pessoal de enfermagem de dois hospitais públicos. Dissertação de Mestrado, Universidade de Brasília, Brasília.

Tamayo, M. R. (2002). Burnout: relações com a afetividade negativa, o coping no trabalho e a percepção de suporte organizacional. Tese de Doutorado, Universidade de Brasília, Brasília.

Tamayo, M. R., Argolo, J. C. T., \& Borges, L. O. (2005). Burnout em profissionais de saúde: um estudo com trabalhadores do município de Natal. Em L. O. Borges (Org.), Profissionais de saúde e seu trabalho (pp. 34-52). São Paulo: Casa do Psicólogo.

Tamayo, M. R., \& Trócoli, B. (2000). Construção e validação da escala de caracterização do burnout (ECB) [Resumo]. Em Sociedade Brasileira de Psicologia (Org.), Resumos de comunicações científicas, XXX Reunião Anual de Psicologia (p. 22). Brasília: SBP.

Tamayo, M. R., \& Trócoli, B. (2005). Validação da escala de caracterização do burnout [Resumo]. Em União Latino América de Psicologia (Org.), Resumos de comunicações cientificas, I Congresso Latino-Americano de Psicologia (p. 27). São Paulo: ULAPSI.

Tripodi, T. (1975). Análise da pesquisa social. Rio de Janeiro: F. Alves.
Recebido em 27.02.07

Primeira decisão editorial em 26.04.09

Versão final em 22.06.09

Aceito em 23.06.09 